\section{Epitope Tag-Antibody Combination Useful for the Detection of Protein Expression in Prokaryotic and Eukaryotic Cells}

\section{BioTechniques 23:96-97 (July 1997)}

Epitope tagging has proven a useful method for monitoring recombinant proteins expressed in either prokaryotic or eukaryotic cells. For this purpose, the epitope should not be present on any of the host cell's proteins, it should not interfere with either structure or function of the tagged protein, and the corresponding antibody must be of high specificity and affinity. To this day, only a few epitope-antibody combinations have been found satisfactory (5).

We describe the successful application of a new epitope-antibody combination. The epitope consists of a 10amino acid sequence motif present in profilin from birch pollen. It is recognized by the monoclonal anti-birch profilin antibody 4A6, which has been characterized as an immunoglobulin $\operatorname{IgG} 2 \mathrm{a}$ (1). Epitope recognition by 4A6 is restricted to profilins of the birch tree family (4) and has been demonstrated in immunoblotting, immunoprecipitation and immunofluorescence $(1,3)$.

A DNA cassette coding for the 4A6 epitope (S F P Q F K P Q E I) (4) with an EcoRI-compatible $5^{\prime}$ end and an XbaI-compatible 3' overhang was generated by annealing the synthetic oligonucleotides BiPro1 (5'-AAT TCC TTC CCA CAG TTT AAG CCT CAG GAA AT-3') and BiPro2 (5'-CTA GAT TTC CTG AGG CTT AAA CTG TGG GAA GG-3'). The resulting doublestranded DNA fragment was cloned into the EcoRI/XbaI-digested vectors $\mathrm{pMal} / \mathrm{c}$ (New England Biolabs, Schwalbach, Germany) and pcDNA3 (Invitrogen, Leek, Netherlands) to produce a prokaryotic and a eukaryotic expression vector, respectively. The resulting constructs $\mathrm{pMal} / \mathrm{BiPro}$ and pcDNA3/BiPro were verified by DNA sequencing. Using the $\mathrm{C}$-terminal birch profilin tag, one can monitor: $(i)$ the expression in transformed $E$. coli of any protein as a fusion protein with the maltose-binding protein (MBP); (ii) its pu- rity after amylose affinity chromatography; and (iii) its integrity after cleaving the N-terminal MBP by factor Xa (according to the instructions by the manufacturer).

We tested the usefulness of pMal/ BiPro in this context by cloning into it the cDNA of mouse adenylyl cyclaseassociated protein (CAP; GenBank ${ }^{\circledR}$ Accession No. L12367). The 1.4-kb DNA fragment was fused in-frame to

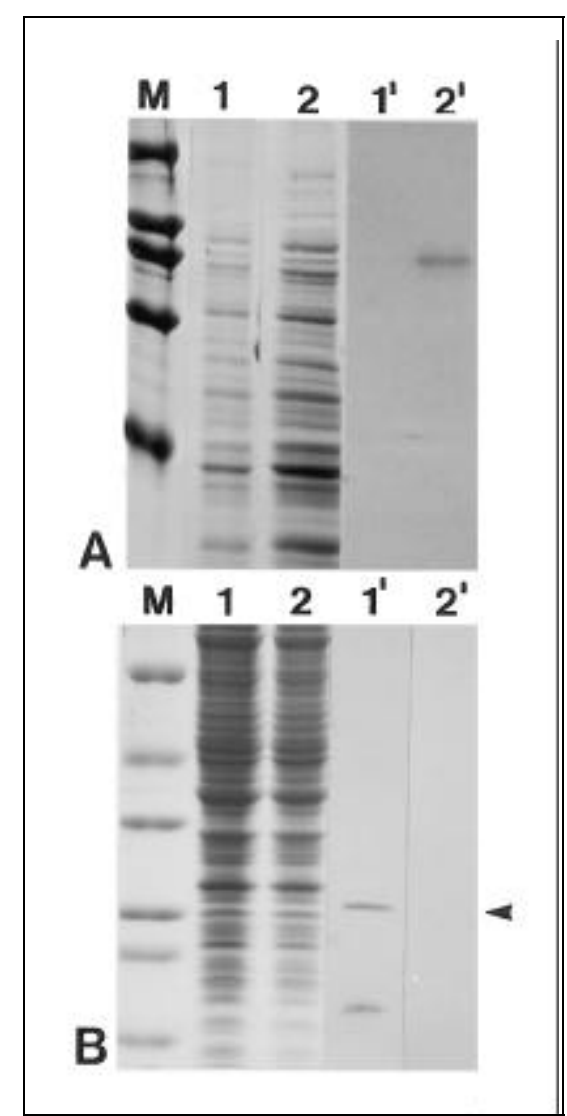

Figure 1. Detection of tagged proteins in prokaryotic and eukaryotic cells. (A) Bacterial lysates of $E$. coli carrying the vector pMal-CAPBiPro were analyzed before (lanes 1 and $1^{\prime}$ ) and after IPTG induction of the bacteria (lanes 2 and $\left.2^{\prime}\right)$ by SDS-PAGE/Coomassie ${ }^{\circledR}$ blue staining (lanes 1 and 2) and by immunoblotting with 4A6 (lanes 1' and 2'). Lane M: molecular weight markers at 45, 66, 97.5, 116 and $205 \mathrm{kDa}$. (B) Detection of the tagged vinculin tail in lysates of transfected $\mathrm{PtK}_{2}$ cells. Coomassie blue-stained gels are shown of lysates from $\mathrm{PtK}_{2}$ cells transfected either with pcDNA3-VTBiPro (lane 1) or with pcDNA3/BiPro (lane 2, control). Lanes 1' and 2': corresponding immunoblots with 4A6. The arrowhead indicates the expected position of the vinculin tail fragment at $29 \mathrm{kDa}$. The lower band corresponds to a degradation product, as identified by a chicken vinculin tail-specific antibody (2). Lane M: molecular weight markers at 20.1, 24, 29, 36, 45 and $66 \mathrm{kDa}$. the MBP and the epitope tag as an EcoRI fragment. The resulting construct (pMal-CAPBiPro) was verified by restriction analysis and DNA sequencing. Expression of the tagged fusion protein was induced with isopropyl- $\beta$-D-thiogalactopyranoside

(IPTG) and monitored by immunoblotting after sodium dodecyl sulfate polyacrylamide gel electrophoresis (SDSPAGE; Figure 1A). The tagged MBPCAP fusion protein $(99 \mathrm{kDa})$ was faithfully and specifically recognized by 4A6 (Figure 1A, lane 2').

To test the eukaryotic expression vector pcDNA3/BiPro, we inserted a sequence encoding amino acids 8581066 of chicken vinculin (GenBank Accession No. J04126) as a HindIII/ EcoRI fragment into the HindIII/ EcoRI-digested pcDNA3/BiPro to generate pcDNA3-VTBiPro. The expression of the tagged polypeptide was monitored in a mammalian epithelial cell line $\left(\mathrm{PtK}_{2}\right)$ and transfected by the $\mathrm{CaPO}_{4}$ precipitation method. Immunoblot analysis with $4 \mathrm{~A} 6$ proved the

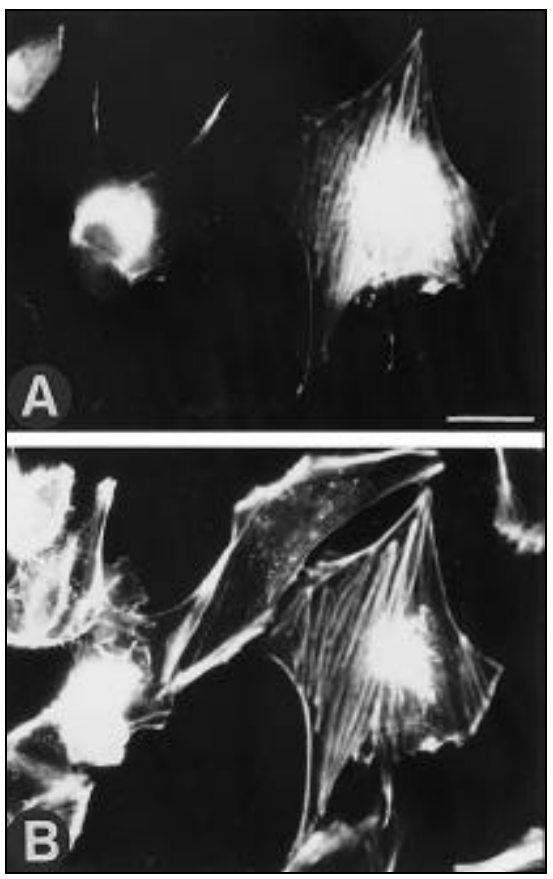

Figure 2. Immunofluorescence of $\mathrm{PtK}_{2}$ cells transfected with pcDNA3-VTBiPro. Cells were stained for the tagged vinculin tail with $4 \mathrm{~A} 6$ and a rhodamine-coupled secondary antibody (A) and for F-actin with fluorescein isothiocyanate (FITC)-phalloidin (B). Note the co-localization of the expressed vinculin tail in stress fibers and in large, perinuclear aggregates with filamentous actin. Bar, $20 \mu \mathrm{m}$. 
presence of the tagged avian vinculin tail in $\mathrm{PtK}_{2}$, seen at the expected position of $29 \mathrm{kDa}$, together with a proteolytic degradation product (Figure 1B). Both proteins were also recognized by a monoclonal antibody specific for the avian vinculin tail (Reference 2; data not shown). In immunofluorescence analysis of the transfected cells, 4A6 identified the vinculin tail fragment localized to actin filament bundles and in large actin filament aggregates (Figure 2 ). This association of the vinculin tail domain with actin filaments in transfected cells has been described previously by our group (unpublished).

In addition, we found that $4 \mathrm{~A} 6$ can be faithfully used to immunoprecipitate BiPro-tagged proteins and as first antibody in enzyme-linked immunosorbent assay (ELISA) and microinjection studies (data not shown). Thus, it should be applicable in a wide range of studies where proteins have to be identified.

\section{REFERENCES}

1.Giehl, K., R. Valenta, M. Rothkegel, M. Ronsiek, H.G. Mannherz and B.M. Jockusch. 1994. Interaction of plant profilin with mammalian actin. Eur. J. Biochem. 226:681-689.

2.Menkel, A.R., M. Kroemker, P. Bubeck, M. Ronsiek, G. Nikolai and B.M. Jockusch. 1994. Characterization of an F-actin-binding domain in the cytoskeletal protein vinculin. J. Cell Biol. 126:1231-1240.

3.Rothkegel, M., O. Mayboroda, M. Rohde, C. Wucherpfennig, R. Valenta and B.M. Jockusch. 1996. Plant and animal profilins are functionally equivalent and stabilize microfilaments in living animal cells. J. Cell Sci. 109:83-90.

4.Wiedemann, P., K. Giehl, S.C. Almo, A.A. Fedorov, P. Steinberger, M. Rüdiger, M. Ortner, M. Sippl et al. 1996. Molecular and structural analysis of a continous birch profilin epitope defined by a monoclonal antibody. J. Biol. Chem. 271:29915-29921.

5.Zentgraf, H., M. Frey, S. Schwinn, C. Tessmer, B. Willemann, Y. Samstag and I. Velhagen. 1995. Detection of histidine-tagged fusion proteins by using a high-specific mouse monoclonal anti-histidine tag antibody. Nucleic Acids Res. 23:3347-3348.
We thank Dr. C. Schwienbacher and M. Lederer for their support and stimulating discussions, C. Wucherpfennig and M. Bock for expert technical assistance and the Deutsche Forschungsgemeinschaft for financial support. Address correspondence to Martin Rothkegel, Cell Biology, Zoological Institute, TU Braunschweig, D-38092 Braunschweig, Germany. Internet: m.rothkegel@tu-bs.de

Received 3 September 1996; accepted 13 January 1997.

Manfred Rüdiger, Brigitte $M$. Jockusch and Martin Rothkegel Technical University of Braunschweig Braunschweig, Germany 